\title{
NAHIJA MOSTAR U SVJETLU PRVIH OSMANSKIH POPISA
}

\author{
Dijana PINJUH \\ Filozofski fakultet \\ Matice hrvatske b.b. \\ $\mathrm{BiH}$ - 88000 Mostar \\ E-pošta: dijana.pinjuh@sve-mo.ba
}

\author{
UDK $94(497.6$ Mostar)"14" \\ 311.3(497.6 Mostar)"14" \\ Pregledni rad \\ Primljeno: 11. svibnja 2015. \\ Prihvaćeno: 10. lipnja 2015
}

\section{Sažetak}

$\mathrm{Na}$ temelju prvih osmanskih popisa u radu se daje prikaz stanja na prostoru novoosnovane nahije Mostar, neposredno nakon osmanskoga osvajanja. Izravna posljedica osvajanja bio je velik broj pustih i polupustih naselja. Povlasticama i oslobađanjem od pojedinih obveza nove su vlasti nastojale privoljeti izbjeglo stanovništvo da se vrati svojim domovima, ali i naseliti novo. Poduzete mjere pozitivno će se odraziti na povratak stanovništva, tako da će samo nekoliko godina nakon osvajanja broj pustih mjesta biti smanjen.

Ključne riječi: osmanski popisi, nahija Mostar, stanovništvo, pusta i naseljena mjesta. 
Osmanski popisi, defteri, predstavljaju vrstu knjige, odnosno registra u koji su unošeni različiti podatci za potrebe državne uprave Osmanskoga Carstva, a koji su se ažurirali i dopunjavali novim podatcima o osvojenim područjima. Postoji više vrsta deftera, ali za proučavanje društvene, gospodarske i demografske povijesti na našim prostorima najznačajnija skupina jesu popisni defteri (tahrir defterleri), koje je sastavljala financijska uprava. U njima su zbirno ili pojedinačno popisivani izvori prihoda određenoga područja, ali i podatci o naseljenim i nenaseljenim mjestima, broju domova, brojnom i imovnom stanju stanovnika, te pravima i obvezama podložnoga stanovništva. Za Osmanlije ti su podatci bili značajni u pogledu izvora državnih prihoda zbog oporezivanja podložnoga stanovništva, a za nas su važni jer nam daju uvid u društvene i gospodarske prilike onoga vremena. ${ }^{1}$ Treba spomenuti da defteri nisu popisi stanovništva i ne daju vjerne podatke o broju stanovnika određenoga kraja, ali ipak donose dragocjene informacije za proučavanje migracijskih procesa, poglavito u prvim godinama nakon uspostave osmanske vlasti.

Prvi osmanski popis koji se dotiče Hercegovine i daje uvid o prilikama neposredno nakon osvajanja bio je prvi sumarni popis sandžaka Bosna, nastao 1468./1469., a u sklopu kojega su bili popisani i do tada osvojeni dijelovi Hercegovine. Međutim, za proučavanje Hercegovine posebnu važnost ima detaljni popis hercego- vačkoga sandžaka, nastao u razdoblju između 1475. i 1477. godine, koji je ujedno prvi i najstariji popis za Hercegovinu. Podatci koje nam donose spomenuti defteri daju barem naslutiti sliku Hercegovine neposredno nakon osvajanja.

Osmanlije su u svojim osvajačkim pohodima koristile prokušanu taktiku koja je za cilj imala slabljenje obrambene i ekonomske snage protivnika. Jurišni odredi, tzv. akindžije provaljivali su na područja, pustošeći i pljačkajući sela i odvodeći narod u sužanjstvo. U takvim je prilikama narod bježao u sigurnije krajeve gdje je opasnost od neprijatelja bila manja ili je nikako nije bilo. Posljedice osmanskih osvajanja i bježanja stanovništva bila su pusta i razrušena sela, te napuštena i neobrađena zemlja. Izuzetak nije bila ni Hercegovina, koja je i prije konačnoga pada 1482. godine bila u velikoj mjeri opustošena i razrušena, a stanovništvo izbjeglo. Do 1475. najveći dio Hercegovine bio je osvojen, a ranije osvojena područja, koja su bila organizirana u vilajet Hersek, od 1470. godine organizirana su u zasebnu administrativnu jedinicu, sandžak. U sudsko-administrativnom pogledu sandžak je bio podijeljen na sudbene jedinice, tzv. kaze ili kadiluke, koji su se sastojali od manjih upravnih jedinica, nahija. Nahija (tur. nahiye) bila je osnovna organizacijska jedinica koja je predstavljala točno utvrđeni prostor jedne teritorijalne jedinice lokalne uprave, a odgovarala je našim srednjovjekov-

1 Nenad Moačanin, Turska Hrvatska. Hrvati pod vlašću Osmanskog Carstva do 1791. Preispitivanja, Matica hrvatska, Zagreb, 1999., str. 10-11; Više o tahrir defterima vidi u: Suraiya Faroqhi, Approaching Ottoman History: An Introduction to the Sources, Cambridge, 1999., str. 86-95. 
nim župama. Nahije su se nazivale ili po imenima starih župa, ili imenom glavne naseljene utvrde u kojoj su smješteni Turci, ili prema glavnom naselju u dotičnoj župi. ${ }^{2}$

U ovome radu ograničit ćemo se samo na nahiju Mostar i na osnovi osmanskih popisa u razdoblju od 1468 . do 1477. prikazati razmjere depopulacije i pustošenja do kojih je došlo kao izravna posljedica osmanskih osvajanja, kao i nastojanja osmanskih vlasti da nasele opustjela mjesta. ${ }^{3} \mathrm{U}$ izvorima nahija Mostar prvi se put spominje 1469. godine. $U$ administrativnom pogledu Mostar je pripadao drinskom, odnosno fočanskom kadiluku, a u njegovu se sastavu posljednji put spominje 1506. godine. Nakon nešto više od deset godina (1519.) Mostar se javlja kao samostalan kadiluk. ${ }^{4}$

Iako su se područja novoosnovanih nahija najčešće preklapala $s$ područjima srednjovjekovnih župa, bilo je i određenih odstupanja. U sastav mostarske nahije upisivana su i mjesta izvan srednjovjekovne župe Večerić, koja je obuhvaćala područja današnjih općina Mostar, Čitluk i Široki Brijeg, ${ }^{5}$ jer osvajanje Hercegovine još nije bilo dovršeno. Tako je u ovom razdoblju, u sklopu nahije Mostar, bio popisan najveći dio zapadne Hercegovine. Treba spomenuti da će prilikom navođenja popisanih mjesta biti uzeto u obzir stanje kakvo su Osmanlije zatekli u 15. stoljeću, a ne današnja administrativna podjela. Mostar je u ovom razdoblju još uvijek trg, odnosno pazar, i u njegovu sastavu nisu mnoga tadašnja mjesta koja danas čine nerazdvojivi dio grada.

\section{Posljedice osvajanja}

Osmanlije su po dolasku organizirali osvojene dijelove u nahije i popisali zatečeno stanje. Usporedo s tim osvojeni dijelovi dodjeljivani su zaslužnim vojnicima na korištenje. Osnovni oblik vlasništva u osmanskoj državi bilo je državno vlasništvo nad zemljom (arâzi-miri), čija je osnovna karakteristika bila pravo turskih spahija na "uživanje određenog iznosa rente". Sultan, kao vlasnik državne zemlje, zaslužnim je vojnicima dijelio veće ili manje posjede. Taj način nagrađivanja vojnika u osmanskom društvu poznat je pod nazivom timarski sustav. ${ }^{6}$ Posjedi su se prema visini prihoda dijelili na: hasove, zeamete i timare, a prema navedenom modelu zemlja je bila podijeljena i u Hercegovini.

2 Hazim Šabanović, Bosanski pašaluk. Postanak i upravna podjela, Svjetlost, Sarajevo, 1982., str. 45-46, 110.

3 Studiju o ovoj temi, ali za prostor jugoistočne Hercegovine, dao je Milenko Krešıć, "Depopulacija jugoistočne Hercegovine izazvana turskim osvajanjem", u: IvicA Lučić (ur.), Hum i Hercegovina kroz povijest, I., Zbornik radova s Međunarodnoga znanstvenog skupa u Mostaru, Hrvatski institut za povijest, Zagreb, 2011., str. 757-778.

4 H. Šabanović, Bosanski pašaluk, str. 142, 188.

5 Pavao AnĐelić - Marijan Sivrić - Tomislav AnĐelić, Srednjovjekovne humske župe, Ziral, Mostar, 1999., str. 176.

6 Avdo SućEsKa, Ajani. Prilog proučavanju lokalne vlasti u našim zemljama za vrijeme Turaka, Naučno društvo SR Bosne i Hercegovine, Djela, knj. XXII., Odjeljenje istorijsko-filološkog nauka, knjiga 14, Sarajevo, 1965., str. 25. 
Iz sumarnoga popisa $1468 . / 1469$. vidimo da su osvojena područja popisana u sastavu nahije Mostar bila uključena u has bosanskoga sandžak-bega, Isa-bega Ishakovića. Osim pazara Mostar u popisu je zabilježeno još 30 naseljenih i 29 pustih mjesta.

Naseljena mjesta su: Podgorani, Hum, Lišani, Prigraj(đ)ani, Zeljuša, Ljubotić, Crnač, Dobrič, Bučići, Potok, Obrše (vjerojatno Orašine na Raškoj Gori), Livač, Kuti, Vrabčić, Donji Suhodol, Zalik, Jasenjan, Cim, Vihovići, Orlac, Donje Zijemlje, Gornje Zijemlje, Gornji Goranci, Donji Goranci, Vlasnić, Rakitno, Sutina, ${ }^{7}$ Rasno, Gradac, Lise.

Kao pusta mjesta navedeni su: Gornji Suhodol, Vituša, Vina (Vojno kod Mostara), Zahum, Rodoč, Baćevići, Stepkovići, Kalošević, Kruševo, Gradac, ${ }^{8}$ Bilešić, To(u)šić, Tati, Jare, Uzarići, Mokro, Kočerin, Ledinac, Lipno, Buhovo, B(o)rotno, Vionica,
Paoča, Prešnevi, Gradac Drugi, Bu(i) hačić, Dobro Selo, K(G)rabavac (vjerojatno današnja Grabova Draga), Opine. ${ }^{9}$

Uzmemo li u obzir da ni mjesta koja su popisana kao naseljena nisu bila prenapučena, jasno je da je i u njima došlo do odljeva stanovništva. U dijelu nahije Mostar ili Köprü Hisar kako je zabilježeno u popisu, od 30 naseljenih mjesta, dva (Rasno i Vlasnić) imaju šest popisanih domova, četiri (Dobrič, Kuti, Zalik i G. Zijemlje) po pet, dok sela Hum, Bučići, Obrše, Jasenjan i Lise imaju manje od pet domova. Sam pazar Mostar imao je 16 popisanih domova. ${ }^{10}$

U nekim je mjestima broj upisanih domova primjetno veći. Tako je u Donjim i Gornjim Gorancima sjeverno od Mostara zajedno upisano 40 domova, Donjim Zijemljima 21, Ljubotiću 14, Lišanima i Rakitnu 13 domova. ${ }^{11} \mathrm{Na}$ razlike u broju popisanih domova dije-

7 Aličić Sutinu smješta sjeverno od Mostara, kao njegovo predgrađe. Međutim, ovdje se ne radi o mostarskom predgrađu, nego o Sutini u općini Posušje. Na taj zaključak upućuje činjenica da se u popisu Sutina navodi poslije Rakitna i prije Rasna, a ne prije mjesta Potok (danas Potoci) ili poslije Vrapčića kako bi bilo logično, s obzirom na redoslijed navođenja i zemljopisni smještaj navedenih mjesta. Ahmed S. Alıčić, Sumarni popis sandžaka Bosna iz 1468./69. godine, Islamski kulturni centar, Mostar, 2008., str. 58, bilj. 961.

8 U popisu iz 1468./1469. pod nazivom Gradac upisana su tri sela i teško je razlučiti koji je Gradac u pitanju. Danas na potezu od Mostara do Imotskog postoji pet sela istoga imena (Gradac kod Širokoga Brijega, Krehin Gradac kod Čitluka, Gradac kod Posušja, zaseok Gradac kod Ljubuškog te selo Gradac kod Imotskog), tako da se ne može sa sigurnošću reći o kojem se Gracu ovdje radi. Aličić je to pokušao utvrditi, ali sve je ostalo na pretpostavkama. Jedino je sigurno da se ne radi o Gracu kod Ljubuškog, budući da Ljubuški tada još nije bio osvojen. A. S. Alıčić, "Lištica pod turskom vlašću u 15. i 16. stoljeću", u: Glasnik Zemaljskog muzeja BiH, Etnologija, n. s., sv. XXIV./XXV., Sarajevo, 1969./1970., str. 101; Isti, Sumarni popis sandžaka Bosna..., str. 163, bilj. 2333; str. 251, bilj. 3485; str. 252, bilj. 3500.

9 A. S. Alıčić, Sumarni popis sandžaka Bosna..., str. 56-58, 163, 250-252. U monografiji Hercegovina Mulić navodi da je u nahiji Mostar u prvom sumarnom popisu bilo 31 pusto mjesto. Jusuf Mulić, Hercegovina, II., Vojna i upravna jedinica Osmanskog carstva (XV i XVI stoljeće), II./I., Sarajevo, 2004., str. 1.

10 A. S. Alıčić, Sumarni popis sandžaka Bosna..., str. 56-58, 163. 
lom je utjecao i sami smještaj navedenih naselja. Mjesta u kojima je zabilježeno više domova bila su udaljena od glavnih putova i na neki način više zaštićena od pogleda turskih službenika, što je vjerojatno utjecalo na povećan broj domova. To posebno vrijedi kada se radi o planinskim mjestima poput Goranaca, Zijemalja ili Rakitna, čemu u prilog govori još jedan podatak. U nahiji Drežnici, sjeverno od Mostara, u samo tri sela koja su činila nahiju popisano je više od 140 domova. Ukupno $143 .{ }^{12}$ Uzmemo li u obzir planinski položaj Drežnice, svojevrsnu izoliranost i udaljenost od glavnih putova, navedena brojka nimalo ne začuđuje.

Izuzetak od naprijed navedenoga jest mjesto Cimljani (Cim), jedno od predgrađa današnjega Mostara, u kojemu je upisano 38 domova. ${ }^{13} \mathrm{No}$, uzmemo li u obzir površinu tadašnjega Cima, navedena brojka također ne iznenađuje. Još prije osmanskoga zauzimanja tadašnji se Cim, koji se u izvorima iz sredine 15 . stoljeća spominje kao Cimiacho ili Cimovski grad, protezao do ušća Radobolje u Neretvu. ${ }^{14} \mathrm{Na}$ tom je prostoru i prije osvajanja morao biti stanovit broj domova. Osim toga, u popis su ulazila samo ona domaćinstva koja su bila oporezivana, ${ }^{15}$ tako da se navedeni broj ne može uzeti kao konačan i potpuno siguran. Vjerojatno je i u drugim mjestima bilo više stanovništva nego što to pokazuju popisi, ali je to teško dokazati jer detaljni popis sandžaka Bosna nije pronađen.

Prema sljedećem popisu koji je uslijedio 1475./1477. broj pustih sela i dalje je veoma velik, a pojavljuju se i neka mjesta koja nisu bila navedena u prvom popisu. Zemlja kao vlasništvo sultana bila je najvećim dijelom dodijeljena spahijama u vidu timara, dok je jedan manji dio bio uključen u hasove sultana $i$, ovaj put, hercegovačkoga sandžak-bega.

Ukupno je u nahiji Mostar 1475./1477. popisano 39 naseljenih mjesta, od čega su dva pripadala u carski has, devet su bila hasovi hercegovačkoga sandžakbega, a 28 su bila dodijeljena kao timari posadnicima tvrđava Ljubuški, Mostar i Blagaj. ${ }^{16}$ Od gore navedenoga broja, devet je sela čije je stanovništvo bilo upisano u rajinskom statusu. To su: pazar Mostar, Počići, Podgorani, Donje Zijemlje, Cim, Rakitno, Gornji i Donji Goranci, Ljubotići i Tati. Sva navedena sela u statusu raje, odnosno njihovi stanovnici, bili su obvezni na davanje rajinskoga poreza ispendža (osobni porez) i sva su bila hasovi hercegovačkoga sandžak-bega. Sela dodijeljena kao timari posadnicima tvrđave Ljubuški, Mostar i Blagaj, bila su oslobođena ispendže. Za Lise i Gradac, koja su bila dijelom carskoga hasa, nisu precizirana nikakva davanja nego samo ukupan iznos, ali je za pretpostaviti da su i ona bila dužna

11 Isto, str. 56, 58.

12 Isto, str. 58.

13 Isto, str. 57.

14 P. AnĐelić - M. Sivrić - T. AnĐelić, Srednjovjekovne humske župe, str. 172-173.

15 H. ŠABAnović, Bosanski pašaluk, str. 142.

16 A. S. Aličıć, Poimenični popis sandžaka vilajeta Hercegovina, Orijentalni institut, Sarajevo, 1985., str. 21, 201-206, 390-395, 399, 406, 438-441, 443, 448-449, 451, 454-456, 481. 
davati ispendžu kao i ostalo stanovništvo koje je bilo u hasovima sultana i sandžak-bega. Zašto je stanovništvo koje je bilo u sklopu timara bilo oslobođeno ispendže, ne može se točno ustvrditi. Popisivač nigdje u defteru ne navodi obrazloženje za takvo što.

Pustih je naselja u popisu iz 1475./1477. u nahiji Mostar zabilježeno čak 19. To su: Stepenkovići, Bahačkovići, Kruševo, Biletići, Uzarići, Mokro, Lipno, Buhovo, Borotine, Vionica, Gradac, ${ }^{17}$ Jare, Paoča, Prešnjevo, Gradac, Bahačići, Gradac, Dobro Selo, Kaloševići. ${ }^{18}$ Dobro Selo, Buhovo i Mokro također su upisana i kao mezre, ${ }^{19}$ a samo kao mezre upisani su Zahum, Skočim i Dračevo. ${ }^{20}$ Selo Uzarići pojavljuje se upisano dva puta. Prvi put kao dio sela s jednim naseljenim domom, koje je dodijeljeno kao timar posadnicima tvrđave Mostar, a drugi put kao pusto. ${ }^{21}$

Broj pustih mjesta u odnosu na prvi popis nešto je manji što je svakako posljedica povratka odbjegloga stanovništva, kao i doseljavanja no- voga. Umjesto 29 napuštenih sela, koliko je zabilježeno 1468./1469., u drugom popisu nalazimo ih 19 nenaseljenih. Usporedimo li popise iz 1468. i 1475. godine vidimo da se pojavljuje 15 mjesta, koja su bila pusta i u prvom popisu. To su: Kruševo, Gradac, Jare, Uzarići, Mokro, Lipno, Buhovo, Borotine, Vionica, Paoča, Bahačići (u prvom popisu navedeno kao Bu(i)hačić), Gradac (ne znamo o kojem je Gracu riječ), Dobro Selo, Stepenkovići i Kalošević.

Kako bi se pusta mjesta ponovno naselila, osmanske su vlasti obećanjima i povlasticama nastojale privući izbjeglo stanovništvo. Poduzete mjere urodile su plodom na što ukazuju podatci o mjestima koja su u ranijem popisu zabilježena kao pusta, a sada su upisana kao naseljena. Tako je u Zahumu zabilježeno jedno, Tatima dva, Kočerinu sedam, u selu Vina četiri i Grabovi osam domaćinstava. ${ }^{22}$ Premda se ne radi o pretjerano velikom broju, to je ipak pokazatelj da je povratak, iako slab, već započeo.

17 U popisu iz 1475./1477. pojavljuju se četiri Graca. Tri su navedena kao pusta, a četvrti je Gradac koji je spomenut i u prvom popisu. Teško je točno utvrditi o kojem se Gracu radi.

18 A. S. Aličić, Poimenični popis sandžaka vilajeta Hercegovina, str. 601-602.

19 Isto, str. 82.

20 Isto, str. 202, 611. Mulić u svojoj monografiji navodi dvije puste mezre u nahiji Mostar, ali je detaljnim pregledom popisa pronađeno više mezri od onoga što Mulić navodi. J. Mulić, Hercegovina. Vojna i upravna jedinica Osmanskog carstva (XV i XVI stoljeće), II./I., str. 1.

21 A. S. Aličıć, Poimenični popis sandžaka vilajeta Hercegovina, str. 449, 601. Za mjesta Brezje, Nerađ i Podvranje navodi se kako ih je još Hamza-beg, prvi hercegovački sandžak-beg, dao kao puste Mrkši i njegovom bratu Mustafi da ih koriste kao zimovališta, a sada su neka od tih mjesta u rukama raje, što znači da su naseljena. Na žalost, ne precizira se koja su to mjesta pa iz toga razloga nisu ni uvrštena u popis pustih, odnosno naseljenih mjesta. Za Nerađe i Podvranje Aličić navodi da se nalaze u općini Čapljina, odnosno Lištica. A. S. Aličıć, Poimenični popis sandžaka vilajeta Hercegovina, str. 83, bilj. 572, 573.

22 A. S. Alıčić, Sumarni popis sandžaka Bosna ..., str. 250-252; A. S. Alıčıć, Poimenični popis sandžaka vilajeta Hercegovina, str. 202, 206, 394-395, 481. 
Promjene u broju naseljenih domova između dva popisa najbolje ilustrira dolje priložena tabela.
Iz popisa je razvidno da je u gotovo svim mjestima popisan veći broj domaćinstava nego nekoliko godina

\begin{tabular}{|l|l|l|}
\hline Naziv naselja & $\begin{array}{l}\text { Broj naseljenih domova prema } \\
\text { popisu iz 1468./1469.3 }\end{array}$ & $\begin{array}{l}\text { Broj naseljenih domova prema } \\
\text { popisu iz 1475./1477.24 }\end{array}$ \\
\hline Podgorani & 11 & 16 \\
\hline Hum & 4 & 8 \\
\hline Lišani & 13 & 18 \\
\hline Prigrađani & 8 & 16 \\
\hline Željuša & 7 & 11 \\
\hline Ljubotić & 14 & 21 \\
\hline Crnač & 10 & 15 \\
\hline Dobrič & 5 & 4 \\
\hline Potok (Potoci) & 10 & 11 \\
\hline Obrše & 4 & 4 \\
\hline Livač & 6 & 9 \\
\hline Kuti & 5 & 10 \\
\hline Donji Suhodol & 8 & 11 \\
\hline Zalik & 5 & 9 \\
\hline Jasenjani & 4 & 5 \\
\hline Mostar & 16 & 19 \\
\hline Cim & 38 & 50 \\
\hline Vihovići & 8 & 12 \\
\hline Orlac & 10 & 13 \\
\hline Donja Zijemlja & 21 & 34 \\
\hline Gornja Zijemlja & 5 & 4 \\
\hline G. i D. Goranci & 40 & 42 \\
\hline Vlasnić & 6 & 10 \\
\hline Rakitno & 13 & 12 \\
\hline Sutina & 9 & 16 \\
\hline Rasno & 6 & 9 \\
\hline Lise & 1 & 5 \\
\hline Drežnica & 143 & 203 \\
\hline & & \\
\hline
\end{tabular}

ranije. U tabeli je, ilustracije radi, na- vidimo koliko su položaj naselja i dovedena i Drežnica, iako tada nije bila dijeljene povlastice utjecale na povradijelom nahije Mostar, ali upravo na tak stanovnika. Stanovnici Drežnice primjeru Drežnice, u kojoj je zabilje- bili su sokolari i oslobođeni gotovo žen najveći porast upisanih domova, svih nameta (harača, ispendže, poreza

23 A. S. Alıčić, Sumarni popis sandžaka Bosna..., str. 56-58, 163.

24 A. S. Alıčrć, Poimenični popis sandžaka vilajeta Hercegovina, str. 10-11, 201-205, 391392, 394-395, 399, 438-441, 448-449, 451, 454-456. 
na sitnu stoku i dr.). Bili su obvezni na plaćanje poreza paušalno, i to jednu filuriju po domaćinstvu, iako nisu bili Vlasi. ${ }^{25}$ Je li i u kojoj mjeri povratak bio zastupljen i u drugim naseljenim mjestima, ili se jednostavno radilo o povećanju broja oporezivanih domova, koja su i u prvom popisu bila naseljena, ali ne i zavedena u defter, ne može se sa sigurnošću ustvrditi.

$\mathrm{Na}$ to da je bilo više stanovnika nego što donose popisi ukazao je Mladen Ančić na primjeru Stoca, koji je, razmatrajući broj mlinova i domaćinstava u popisu iz 1477., došao do zaključka da je Stolac morao imati više stanovnika od onoga što je zabilježeno. ${ }^{26}$ Primijenimo li isti obrazac i za neka mjesta u mostarskoj nahiji u kojima su zabilježeni mlinovi, dolazimo do istoga zaključka. Mlinovi su zabilježeni u Mostaru, Cimu, Lisama i Potocima. Tako je u Mostaru popisano 19 domaćinstava, jedan neoženjen i tri mlina, Cimu 50 domaćinstava i četiri mlina, od čega su dva bila zapuštena, Lisama pet domaćinstava i četiri mlina te Potocima 11 domaćinstava, dva neoženjena i pet mlinova. ${ }^{27}$ Usporedimo li broj mlinova i domaćinstava, očit je njihov nerazmjer, što posebno upada u oči kada su u pitanju Lise. Gotovo je nevjerojatno da je na pet domaćinstava, koliko ih je upisano u Lisama, bilo potrebno četiri mlina, od kojih su svi bili u funk- ciji. Upravo taj podatak navodi na zaključak da je u Lisama moralo biti više naseljenih domova od popisanih. Čak i ako pretpostavimo da su se mlinovima služili i stanovnici okolnih sela, opet je taj broj nerazmjeran, jer je većina sela oko Lisa bila pusta ili polupusta. Za Mostar, Cim i Potoke vrijedi jednako. I u ovim je mjestima moralo biti više stanovnika, odnosno domaćinstava od navedenoga. Ostaje otvoreno pitanje o kojim se brojkama radilo, jer, kako je već spomenuto, osmanski popisi bilježili su samo one domove koji su bili oporezivani.

Osim već navedenih pustih sela na području Mostara nalazimo podatke i o napuštenim vinogradima. Tako u prvom popisu iz 1468. godine u nahiji Mostar nalazimo devet zapuštenih vinograda. U selu Podgorani od tri hasa vinograda jedan je zapušten, u Željuši su navedena tri zapuštena vinograda, u Livču dva, Kutima jedan, u Vrapčićima od dva hasa vinograda jedan je obrađen a drugi zapušten i u Vlasniću jedan je hasa vinograd zapušten. ${ }^{28}$

U popisu iz 1475. zabilježeno je 13 zapuštenih vinograda, ali neki od njih su kao takvi bili popisani i u prvom popisu. To su vinogradi u Željuši i Livču gdje ih je zabilježen jednak broj zapuštenih kao i ranije, ukupno pet. ${ }^{29}$ Zanimljivo je da u selu Donji Suhodol

25 A. S. Alıčić, Sumarni popis sandžaka Bosna..., str. 58, bilj. 963; A. S. Alıčıć, Poimenični popis sandžaka vilajeta Hercegovina, str. 10.

26 Mladen Ančić, "Kasnosrednjovjekovni Stolac", u: Povijesni prilozi, 29, Zagreb, 2005. str. 47-50.

27 A. S. Aličić, Poimenični popis sandžaka vilajeta Hercegovina, str. 201-204, 399, 439440.

28 A. S. Aličić, Sumarni popis sandžaka Bosna..., str. 56-58.

29 A. S. Alıčić, Poimenični popis sandžaka vilajeta Hercegovina, str. 440-441. 
nalazimo šest zapuštenih hasa vinograda, dok je u prvom popisu u istom selu zabilježen jedan hasa vinograd i to obrađen. Isto tako u selu Kuti, umjesto jednoga zapuštenog vinograda, koliko je zabilježeno 1468. godine, sada nalazimo dva zapuštena. ${ }^{30}$ Kako i zašto je došlo do ovih promjena možemo samo nagađati. Ili u vrijeme popisa nije još bio upisan novi vlasnik, ili su spomenuta sela ostala bez raje koja bi ih obrađivala, što je sve zajedno utjecalo na pad vinogradarstva.

Kako bi riješili problem pustih sela, kao i neobrađene zemlje, osmanske su vlasti nastojale takva mjesta ponovno naseliti. U tome su im poslužili kršćani. Osmanski ih izvor najčešće naziva vojvode. Riječ je o stanovništvu koje je imalo vlaška prava - kojima se, uz jamstvo sigurnosti i određene povlastice, daju napuštene zemlje na korištenje. Primjer jednoga takva sporazuma nalazimo u popisu iz 1475./1477. iz kojega saznajemo kako je hercegovački sandžak-beg Hamza-beg, vojvodi Vladimiru dao na uživanje napuštene baštine na mezrama Dobro Selo, Buhovo, Mokro, Ledinac, Kongora, Humljani, Čraštani, Šal i Turjak. Od Hamzabegova nasljednika Sinan-bega, isti vojvoda dobio je i tapiju na zemlju Rakit, ali pod uvjetom da se nastani i boravi u carskoj zemlji te da na spomenute zemlje nastani i one koji će ih obrađivati. Isto tako, vojvoda je mogao dati spomenute zemlje svakome tko dođe sa strane. ${ }^{31}$ Puste baštine u selu Kruševo u okolici Mostara koje su ranije pripadale Vukašinu Stepkoviću i Vuku Pavčiću, dobili su knez Herak i njegovi nasljednici od Paše Jigit-bega. ${ }^{32}$

Pojedina mjesta dodjeljivana su kao baštine ili zimovališta džematima iz drugih nahija. Tako je džematu $\mathrm{Vu}$ kića Krmpotića koji je upisan u nahiji Humska zemlja, Sinan-beg starim posjednicima (Vukiću, Radosavu i Vučhini, odnosno njihovim džematima) vratio napuštene baštine Ledinac, Veselivštak, Buhovo i Borajna u okolici Gruda, koji su to prihvatili pod uvjetom da ih iskorištavaju kao zimovališta kao što su činili i ranije. ${ }^{33}$

Samo u sklopu mostarske nahije upisano je 16 džemata, tj. zajednica, koji su u velikom broju naselili napuštena mjesta s desnu stranu Neretve. Najveći od njih bio je džemat već spomenutoga vojvode Vladimira, koji je imao 82 domaćinstva i 14 domova neoženjenih i džemat Opanak, knez Vladko, koji je imao 44 domaćinstva i 18 domova neoženjenih. Ostali su džemati malobrojniji i brojili su od dva do 30 domova. ${ }^{34} \mathrm{Za}$ džemat vojvode Vladimira ne navode se mjesta ljetnoga i zimskoga boravka, za razliku od nekih drugih, manjih džemata. Tako znamo da je (H)raška Gora upi-

30 Isto, str. 439, 451.

31 Isto, str. 82. Za mezre Ledinec, Kongora i Humljani autor nije siguran gdje se nalaze, ali ih smješta na područje južno od Gruda, dok za mezru Šal pretpostavlja da se radi o današnjoj Tihaljini u općini Grude. A. S. Alıčıć, Poimenični popis sandžaka vilajeta Hercegovina, str. 82, bilj. 566, 568-569.

32 Isto, str. 604.

33 Isto, str. 89-90.

34 Isto, str. 81-89. 
sana kao zimovalište za vlaški džemat Dobromirac, Vukić, sin Stipana. ${ }^{35} \mathrm{U}$ Kruševu, čiju jednu trećinu i posjeduju, zimuju pripadnici džemata Radoja, sina Žibine (ili Šibine). Biletići su također zimovalište i to Radosava, sina Brijuša u džematu Radibrada, sina Ljubića. ${ }^{36}$ Ostala mjesta koja su navedena kao zimovališta ili ljetovališta pojedinih džemata nalaze se izvan nahije Mostar pa ih ovdje nismo navodili. Vlaške zajednice s lijevu stranu Neretve popisivač ne bilježi.

Nema sumnje da je naseljavanje utjecalo na smanjenje broja pustih sela. Međutim, kada je riječ o depopulaciji u ranom razdoblju, ovdje valja spomenuti zaključak do kojega je došao Evgenij Radušev za Rodopski kraj u 15. stoljeću. Prema njegovu mišljenju, moguće je da je bilo i naseljenih mjesta koja nisu popisivana, jer potrebe za plaćanjem vojničke klase nisu još bile tolike. Radušev se poziva na Veru Mutafčievu koja je došla do istih rezultata za Vidinski kraj kao i on za Pomake u Rodopima, a to je da između 1454. i 1560. nekoliko stotina sela nije bilo popisivano, premda su bila naseljena i u funkciji. ${ }^{37}$ Čini se da se popisivalo samo ona mjesta koja su bila pod timarima i zeametima spahija. Kako je rastao broj spahija, tako se u kasnijim popisima javlja sve više novih-starih sela i stanovnika. Ovo samo pokazuje da kolonizacija, iako je imala značajnu ulogu u naseljavanju pustih mjesta, ne objašnjava i ne iscrpljuje ovaj problem u cijelosti. U popisima koja su ovdje bila uzeta u razmatranje također se pojavljuju neka nova-stara mjesta. To je slučaj s mjestima Čemljani, koje je danas nepoznato pod tim imenom, te Dobrč kod Mostara, ${ }^{38}$ koje je i danas naseljeno. Nijedno od navedenih mjesta ne spominju se u prvom popisu, iako su već tada, barem kada je u pitanju Dobrč, morala biti osvojena, na što upućuje činjenica da su susjedna naselja bila zavedena u defter. U oba popisa unošena su i pusta mjesta, ali ni Čemljani ni Dobrč nisu upisana kao takva, tako da s pravom možemo smatrati da u vrijeme prvoga popisa nisu bila upisana i zavedena kao posjed timarnika, iako su već tada postojala i bila naseljena. To će se dogoditi tek nekoliko godina kasnije kada je porastao i broj spahija kao i posadnika tvrđava kojima je trebalo osigurati prihode.

Ovdje valja spomenuti još jedan podatak koji se pojavljuje u spomenutim defterima. Mjesta Bučići i Vrapčići u prvom su popisu navedena kao naseljena i u sastavu hasa bosanskoga sandžak-bega Isa-bega Ishakovića, dok se naselja Rodoč i Opine navode kao pusta. ${ }^{39} \mathrm{U}$ drugom ih popisu nigdje ne nalazimo upisane. Da se radi o mjestima koja su danas nepoznata, mogli bi za Rodoč i Opine zaključiti da su zbog nedostatka stanovništva nestala ili stopljena sa susjednim mjestima pod drugim imenom. Međutim, i

35 Isto, str. 89.

36 A. S. Aličić, "Lištica pod turskom vlašću u 15. i 16. stoljeću", str. 116-118.

37 Evgeni Radušev, Pomacite. Hristijanstvo i isljam v Zapadnite Rodopi s dolinata na $r$. Mesta, XV-30-te godini na XVIII vek., Čast I, Sofia, 2005., str. 421-422.

38 A. S. Aličić, Poimenični popis sandžaka vilajeta Hercegovina, str. 394, 481.

39 A. S. AlIčrć, Sumarni popis sandžaka Bosna..., str. 56-57, 250, 252. 
jedno i drugo mjesto danas postoje pod istim imenima. Za pretpostaviti je da su oba sela još u vrijeme kada je završen popis 1477. bila naseljena, ali ne i popisana. Razlog tomu opet valja tražiti u potrebama vojničke klase koje u ovo vrijeme još nisu bile tolike da bi sva naseljena mjesta bila dodijeljena kao timari. Za Vrapčiće i Bučiće najizglednije je objašnjenje da nakon smrti bosanskoga sandžakbega, u čijem hasu su bila popisana 1468., zbog nedostatka timarnika kasnije nisu upisana ni u čiji posjed. Kako je vrijeme odmicalo i rastao broj spahija, to će se mijenjati, jer krajem 16. stoljeća Opine, Vrapčiće i Bučiće nalazimo upisane kao timare posadnika tvrđave Mostar. ${ }^{40}$ Jedino Rodoč nije zaveden kao timar, nego kao mahala s popisanim baštinama. ${ }^{41}$ Usporedimo li popis iz 1585. vidimo da se pojavljuju i druga mjesta koja ne nalazimo u popisima iz 15 . stoljeća, iako su već tada morala biti osvojena. Sve navedeno upućuje na to da je i u Hercegovini bilo više spahija u prvoj polovici 16. stoljeća nego na početku, što baca novo svjetlo o razmjerima depopulacije, odnosno kasnijega povratka izbjegloga stanovništva.

\section{Zaključak}

Kao i sva druga osvajanja u povijesti i osvajanja Osmanlija nosila su sa sobom raseljavanje, pustoš i razaranje.
Stanovništvo potaknuto obećanjima i povlasticama novih vlasti malo-pomalo počinje se vraćati u svoje domove, iako je i dalje ostao velik broj domova u koje se njihovi žitelji više nikada nisu vratili. Iako je povratak u početku bio neznatan, on će s vremenom postati intenzivniji, a u naseljavanju pustih mjesta važnu će ulogu imati i vlaško stanovništvo, čije je naseljavanje na prostor Hercegovine u određenoj mjeri započelo i prije osvajanja. O točnim brojevima ovdje je iluzorno govoriti jer ni ovi popisi, unatoč vrijednosti i podatcima koje donose, nisu i ne mogu biti pouzdan izvor kada je u pitanju brojno stanje stanovništva određenoga mjesta ili kraja. U popise su ulazila samo domaćinstva koja su bila pod timarima i zeametima spahija, što pokazuju i naprijed izneseni podatci.

Prema podatcima koje donose osmanski popisi vidljivo je da položaj stanovništva nije u tolikoj mjeri nepovoljan koliko se moglo očekivati $s$ obzirom na smjenu vlasti i promjene do kojih je došlo nakon osvajanja. Mnogi stanovnici zadržali su ili dobili određene povlastice, što je umnogome olakšavalo život. Iako takvo stanje ne će potrajati, to će u prvim godinama nakon osvajanja, a i kasnije, biti važan čimbenik koji će utjecati na povratak staroga i naseljavanje novoga stanovništva.

40 A. S. Alıčić, Opširni katastarski popis za oblast Hercegovu iz 1585. godine., II., Dobra knjiga, Sarajevo, 2014., str. 295-296, 318.

41 Isto, str. 293. 
Nahiye* of Mostar in the light of the first Ottoman

censuses

\section{Summary}

Based on the first Ottoman censuses after the conquest of Bosnia and Herzegovina, the major part of the paper gives an overview of the situation in the newly formed nahiye of Mostar. The conquest resulted in a large number of deserted and half-deserted settlements. With privileges and release from certain duties the new authorities tried to make the exiled population return to their homes, but also to populate the area with new inhabitants. The measures that were taken reflected positively on the return of the population, therefore only a few years after the conquest the number of deserted places was reduced. Although it would be expected to find all the conquered places recorded, it was not quite so. Only the places and homes that were burdened with feudal dues were included into census, therefore it is difficult to estimate the precise number of inhabited villages and households.

Keywords: Ottoman censuses, nahiye of Mostar, population, deserted and populated places.

* subdistrict 